\title{
Pathological differences between clinically suspected and unsuspected gallbladder carcinoma: A 5- year retrospective study
}

\author{
Hazarika P. ${ }^{1}$, Deka R. ${ }^{2}$, Sharma M.K. ${ }^{3}$ \\ ${ }^{1}$ Dr. Prabir Hazarika, Assistant Professor, ${ }^{2}$ Dr. Rasadhar Deka, Associate Professor; above both authors are attached with \\ Department of Pathology, Jorhat Medical College, Jorhat, Assam, India, ${ }^{3}$ Dr. Manoj K Sharma, Pathologist and \\ Laboratory Director, Alcare Diagnostic and Research Centre, Guwahati, Assam, India
}

Address for Correspondence: Dr. Prabir Hazarika, Department of Pathology, Jorhat Medical College and Hospital, Jorhat, Assam, India. Email: prabirhazarika@gmail.com

\begin{abstract}
Introduction: Gallbladder carcinoma frequently presents as incidental finding in routine cholecystectomy specimens operated for gallstone diseases. The reason behind unrecognition of these tumors pre and intraoperatively and its significance need evaluation. Objective: We have done a 5 years retrospective study from December 2011 to November 2016 in a referral centre to evaluate the pathological features of unsuspected gallbladder carcinoma and to compare these with those of suspected carcinomas. Methods: A total record of 74 cases of gallbladder carcinomas are retrieved from the archives. These are 54 whole gallbladder specimens of simple and extended cholecystectomies and 24 small tissue pieces of gallbladder. Out of 54 whole gallbladder specimens 30 are clinically unsuspected and 24 are suspected carcinomas. Result: Majority of the unsuspected group have diffusely thickened gallbladder wall as their sole gross presentation or no grossly identifiable lesion at all. On the other hand, suspected gallbladder carcinomas have presented mostly as localized wall thickening, thickened wall with invasion of the adjacent structures or large intraluminal mass. Adenocarcinoma was the commonest histological type in suspected and exclusive type in unsuspected group. Most of the unsuspected carcinomas are well differentiated in contrast to the suspected carcinomas which are mostly poorly differentiated followed by almost equal prevalence of moderately differentiated and well differentiated tumors. Half of the unsuspected tumors are limited to gallbladder and no cases of pT4 stage are present. On the contrary, only one fourth of cases of the suspected carcinomas are limited to gallbladder and another one fourth are in pT4 stage. Conclusion: Unsuspected gallbladder carcinoma show different gross presentation and also tend to be better differentiated and in earlier stages than suspected carcinomas.
\end{abstract}

Keywords: Gallbladder, Adenocarcinoma, Unsuspected

\section{Introduction}

Gallbladder carcinoma is the $20^{\text {th }}$ most common cancer in the world [1]. The highest incidence of gallbladder carcinoma is seen in South America and Asia, and the lowest incidence in Africa. Chile has the highest incidence (age standardized rate 9.7 per 1 lakh population) followed by Bolivia and Korea. Korea has the highest incidence of gallbladder carcinoma in male (7.8 per 1 lakh) and Chile has in female (12.8 per 1 lakh). High incidences are also reported from women in Delhi (India), South Karachi (Pakistan), Japan and Quito (Equador) [2]. Incidence of gallbladder cancer is

Manuscript received: $10^{\text {th }}$ June 2017

Reviewed: $20^{\text {th }}$ June 2017

Author Corrected: $30^{\text {th }}$ June 2017

Accepted for Publication: $7^{\text {th }}$ July 2017 high in North, East and North East India, particularly in Delhi, Assam (Dibrugarh, Kamrup Urban and Cachar district), Tripura and Kolkata [3].

Gallbladder Cancer is a disease of adult and occur more commonly in female than male [4,5]. Many of the cases are not suspected clinically and are discovered incidentally during histopathological examination of gallbladder for gallstone diseases [6-16].

Gallbladder carcinomas are notorious for presenting in an advanced stage with attendant dismal prognosis $[4,6,11,12,17]$. Asymptomatic Cancer progression might be the major cause for this untoward event. In a 
highly prevalent zone, a relatively high proportion of unsuspected gallbladder carcinoma affects decision making for proper management in a large number of patients.

We have done a 5 year retrospective analysis to elucidate the causes for this clinical entity and also to evaluate the pathological significance of a missed out unsuspected carcinoma received after cholecystectomy due to some other reason.

\section{Methods and Material}

This is a 5 year retrospective study in a referral centre from December, 2011 to November, 2016. All the case records of gallbladder carcinomas from the registrar and the corresponding blocks and slides have been retrieved.

A total of 74 cases of gallbladder carcinomas are found, out of which 54 are whole gallbladder specimens (simple cholecystectomies with or without omentum andlor lymph nodes and extended cholecystectomies) and 20 are small tissue pieces of gallbladder.

Grossing \& reporting including staging had been done using standard recommendations [18,19]. Suspected carcinomas include all the carcinomas that were suspected clinically either preoperatively or intraoperatively. Unsuspected gallbladder carcinomas are those carcinomas which are first recognized during gross pathological examination or on microscopy. 30 out of 54 whole gallbladder specimens were not clinically suspected of carryings cancer. The 24 small tissue pieces were all from suspected gallbladder carcinomas.

All the carcinoma specimens are considered for assessment of age, sex, histological type and grade, but only whole gallbladder specimens are considered for study of gross morphology, stages of carcinoma and correlation of grades with stages. Normal gallbladder wall thickness measures up to $0.3 \mathrm{~cm} \mathrm{[20].} \mathrm{So,}$ gallbladder wall more than $0.3 \mathrm{~cm}$ thick is considered to be thickened gallbladder wall.

The term diffuse thickening is used to mean diffuse increase in thickness of wall without any grossly recognizable site of tumor. This group is again divided into mild $(0.4 \mathrm{~cm}$ to $0.6 \mathrm{~cm})$ moderate $(0.7 \mathrm{~cm}$ to $10 . \mathrm{cm})$ and marked $(>10 . \mathrm{cm})$ thickening.

The term 'no gross lesion' means that gallbladder wall is grossly unremarkable. In assessment of PT0 nonpapillary tumors inflammatory atypia due to acute cholecystitis is excluded. The data are presented in table format for description and draw summary.

\section{Result}

\section{Age and sex distribution:}

Table 1. Shows the age and sex distribution of the suspected and unsuspected gallbladder carcinoma patients.

\begin{tabular}{|c|c|c|c|c|}
\hline \multirow{2}{*}{ Age group } & \multicolumn{2}{|c|}{ Unsuspected } & \multicolumn{2}{c|}{ Suspected } \\
\cline { 2 - 5 } & Male & Female & 0 & 1 \\
\hline$<30$ years & 0 & 1 & 0 & 8 \\
\hline $30-<40$ years & 2 & 3 & 4 & 10 \\
\hline $40-<50$ years & 0 & 7 & 1 & 7 \\
\hline $50-<60$ years & 3 & 4 & 2 & 1 \\
\hline $60-<70$ years & 3 & 6 & 1 & $\mathbf{3 6}$ \\
\hline$>70$ years & 0 & $\mathbf{2 2}$ & $\mathbf{8}$ & 7 \\
\hline Total & $\mathbf{8}$ & & & \\
\hline
\end{tabular}

It is seen that gallbladder carcinomas are seen over a wide age range of 30 years to 70 years. The mean ages for the suspected and unsuspected groups are 50.5 years and 47.7 years respectively. Unsuspected cancers are 2.7 times and suspected cancers are 4.5 times commoner in females. 


\section{Gross morphology:}

Table 2- displays the distribution of different type of gross morphology among the cases.

\begin{tabular}{|c|c|c|}
\hline Gross Pattern & Unsuspected & Suspected \\
\hline Diffuse wall thickening & 9 & 2 \\
\hline Localized wall thickening & 5 & 6 \\
\hline Thickened wall with invasion of liver and omentum & 0 & 6 \\
\hline Papillary lesion without wall thickening & 1 & 3 \\
\hline Papillary lesion with wall thickening (localized or diffuse) & 4 & 1 \\
\hline Large intraluminal mass & 0 & 4 \\
\hline Induration of wall without thickening & 1 & 1 \\
\hline No grossly indentifiable lesion & 10 & \\
\hline Total & 30 & 24 \\
\hline
\end{tabular}

It is seen that unsuspected group have mostly presented with diffuse wall thickening $(30 \%)$ and no grossly identifiable lesion $(33.3 \%)$. Some cases have also shown localized wall thickening $(13.3 \%)$. On the other hand suspected group have mostly presented as localized wall thickening (25\%), thickened wall with invasion of liver and omentum (25\%), large intraluminal mass (16.7\%) and papillary lesion without wall thickening. Out of the unsuspected diffuse thickening group, 6 cases have mild and 3 have moderate wall thickening. On the other hand suspected diffuse thickening group show one each in mild and moderate wall thickening.

Histological type of the tumor- It is seen that all the 30 unsuspected carcinomas and 40 of 44 suspected carcinomas are conventional adenocarcinomas including papillary type. Rest of the suspected carcinomas are one each of squamous cell carcinoma, small cell carcinoma, clear cell adenocarcinoma and signet ring cell adenocarcinoma.

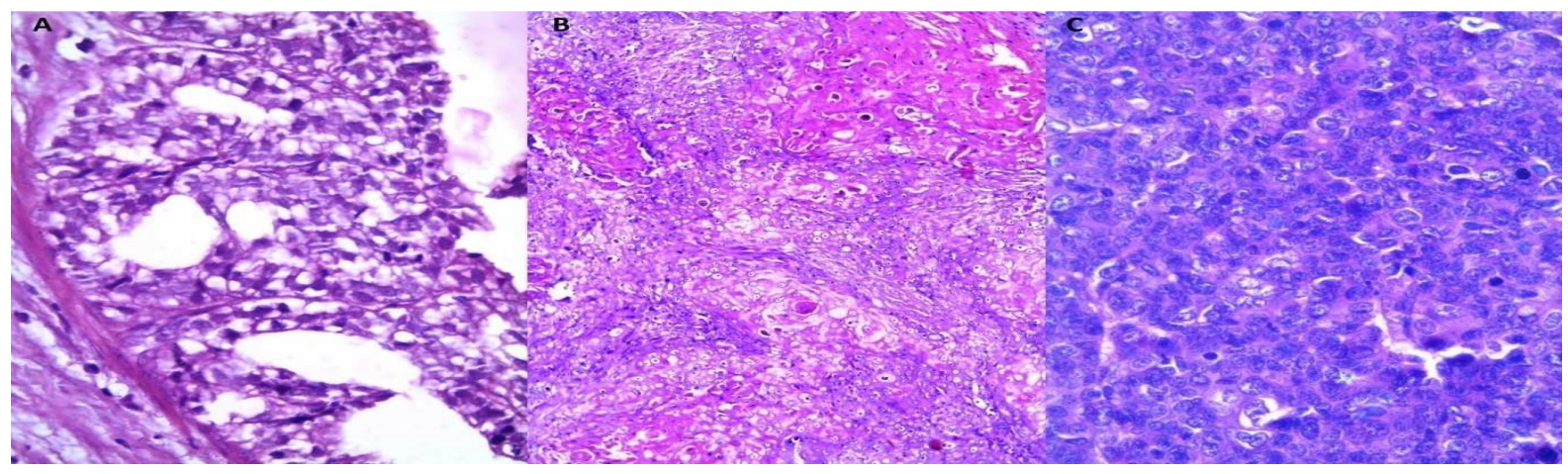

Figure-1: Some unusual histological types of gallbladder cancer. A. Clear cell adenocarcinoma (H \& E, 40X). B. Squamous cell carcinoma (H \& E, 10X). C. Small cell carcinoma (H \& E, 40X)

Grades of the tumor- It is found that $19(63.3 \%)$ of unsuspected tumors are well differentiated, $6(20 \%)$ are moderately and $5(16.7 \%)$ are poorly differentiated. The corresponding figures for suspected cancers are $13(29.4 \%), 12(27.3 \%)$ and $19(43.2 \%)$ respectively

\section{Stages of the tumors:}

Table-3: Shows the distribution of stages of the tumors in each grade

\begin{tabular}{|c|c|c|c|c|c|c|}
\hline Grades Stages & pT 0 & pT 1 & pT 2 & pT 3 & pT 4 & Total \\
\hline Well differentiated (including papillary) & $6(3)$ & $3(1)$ & $5(2)$ & $5(2)$ & $0(0)$ & $19(8)$ \\
\hline Moderately differentiated & $0(0)$ & $1(0)$ & $0(0)$ & $5(2)$ & $0(3)$ & $6(5)$ \\
\hline Poorly differentiated & $0(0)$ & $0(0)$ & $0(0)$ & $5(8)$ & $0(3)$ & $5(11)$ \\
\hline Total & $\mathbf{6 ( 3 )}$ & $\mathbf{4 ( 1 )}$ & $\mathbf{5 ( 2 )}$ & $\mathbf{1 5}(12)$ & $\mathbf{0}(6)$ & $\mathbf{3 0}(\mathbf{2 4})$ \\
\hline
\end{tabular}

The figures in brackets are for suspected cases and those without brackets are for unsuspected cases. 
Research Article

Table 3 Shows that well differentiated tumors are predominantly limited to gallbladder, but moderately differentiated tumors have mostly and poorly differentiated tumors have exclusively extended beyond gallbladder in both unsuspected and suspected groups.

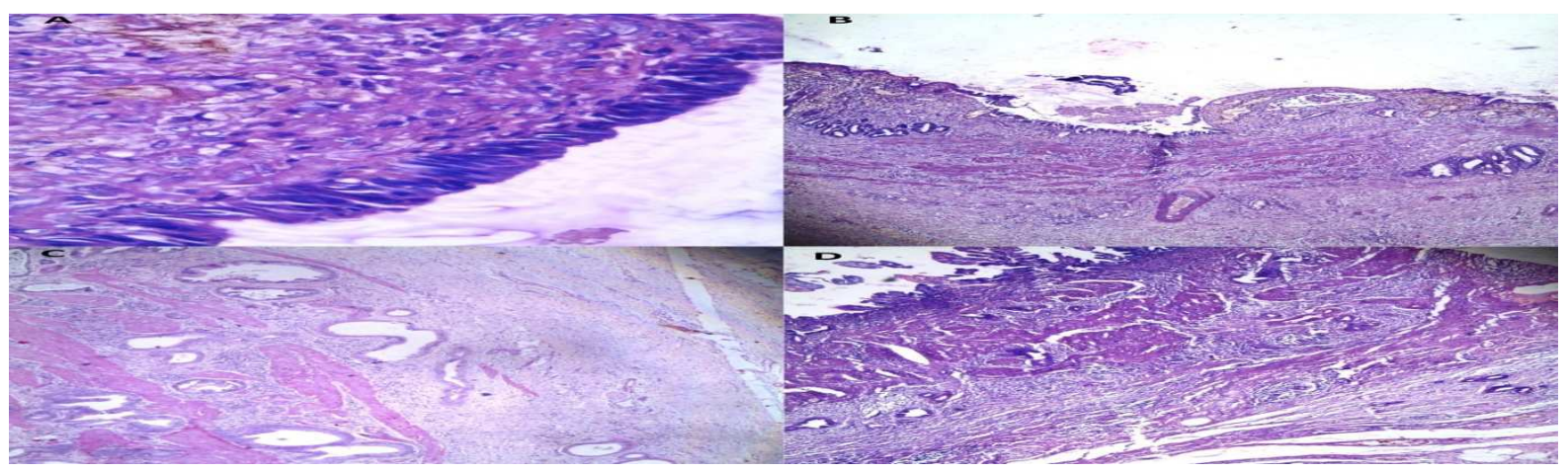

Figure-2: Photomicrograph displaying stages of gallbladder cancer. A. Flat dysplasia or pT0 (H \& E, 40X) B. Stage pT1 tumor infiltrating the muscularis propria partially $(\mathrm{H} \& \mathrm{E}, 4 \mathrm{X}) \mathrm{C}$. Stage pT2 tumor infiltrating the muscularis propria completely but not up to the serosa (H \& E, 10X) D. Stage pT3 tumor infiltrating upto serosa (H \& E, 4X)

Table-4: Relative percentages of suspected and unsuspected tumors in each stage

\begin{tabular}{|c|c|c|c|c|c|}
\hline \multirow{2}{*}{ Category } & \multicolumn{5}{|c|}{ Stages } \\
\cline { 2 - 6 } & pT0 & pT1 & pT2 & pT3 & pT4 \\
\hline Unsuspected & $20 \%$ & $13.3 \%$ & $16.7 \%$ & $50 \%$ & $0 \%$ \\
\hline Suspected & $12.5 \%$ & $4.2 \%$ & $8.3 \%$ & $50 \%$ & $25 \%$ \\
\hline
\end{tabular}

Table 4 shows that half of all unsuspected tumors are detected in a stage limited to gallbladder with a high proportion of pT0 and pT1 stage tumors. But only $25 \%$ of the suspected tumors are detected in a stage limited to gallbladder. No unsuspected tumors are present in pT4 stage, but $25 \%$ of the suspected tumors are found in this stage.

\section{Discussion}

Unsuspected carcinomas constitute $40.5 \%$ of all gallbladder carcinomas in our study. The mean age for suspected group is 47.7 years and that for unsuspected group is 50.5 year. This is comparable to study from Nepal (mean age of 54 year) [5]. However studies from North America (Canada) and South America (Chile) have reported average age of presentation 61.23 year and 61.5 year respectively[4,11]. This disparity could probably be attributed to racial and environmental influences. We have found that unsuspected gallbladder carcinomas are 2.75 times and suspected carcinomas are 4.5 times more common in female. Several other studies have also shown that gallbladder carcinomas are 4-5 times more common in female $[4,11]$. However, we have found that female predominance is less marked in unsuspected than suspected cancers which require further studies for confirmation.

In the present study, most of the unsuspected gallbladder carcinomas have presented with diffuse thickening of the wall $(30 \%)$ and no grossly identifiable lesion (33.3\%). Relatively higher proportion of carcinomas presenting with diffuse wall thickening and with no grossly identifiable lesion have been reported in some other studies also[4,10]. Roa et al have reported diffuse thickening in $12.3 \%$ and unapparent lesion in $38.8 \%$ of their cases as gross presenting features. On the other hand localized wall thickening (25\%), thickened wall with invasion of the sorrounding structures $(25 \%)$ and large intraluminal mass (16.7\%) represents greater portion of suspected gallbladder carcinomas in the present study.

Adenocarcinoma is the most common histological type of gallbladder carcinoma [4,5,9,20]. All the unsuspected carcinomas and $95 \%$ of the suspected carcinomas in the present study are adenocarcinoma. Suspected group show $29.5 \%$ well differentiated, $27.3 \%$ moderately differentiated and $43.2 \%$ poorly differentiated tumors. Similar results are reported by Ivan Roa et al[4]. They have found $21.5 \%$ of their cases to be well differentiated and $78.5 \%$ cases to be moderately 
Research Article

and poorly differentiated. However the clinically unsuspected group in our study show a different picture. $63.3 \%$ cases of unsuspected group are well differentiated and rest are almost equally divided between moderately differentiated and poorly differentiated grades.

In the present study half of the unsuspected carcinomas are limited to gallbladder and a significant portion of these are carcinoma in situ and early carcinoma limited to muscle layer only. No cases of PT4 are present. But the suspected carcinomas show only one fourth of the cases limited to gallbladder and another one fourth in PT4 stage.

Table-5: Stage distribution of gallbladder carcinoma cases in multiple studies found in literature expressed as percentages of total cases.

\begin{tabular}{|c|c|c|c|c|c|}
\hline Study & PT 0 & PT 1 & PT 2 & PT 3 & PT 4 \\
\hline Kimura $\mathrm{W}$ et al[6] & & & & & \\
\hline Asymptomatic cases $(15)^{*}$ & 13.3 & 20 & 46.7 & 20 & 0 \\
\hline Symptomatic cases $(65)^{*}$ & 0 & 0 & 0 & 9.3 & 90.7 \\
\hline $\begin{array}{c}\text { L. Hu et al[13] (38)* } \\
\text { (All cases are unsuspected) }\end{array}$ & - & 31.7 & 36.8 & 28.9 & 2.6 \\
\hline M. D' Hondt et al[11] & & & & & \\
\hline Incidental $(30)^{*}$ & 0 & 10 & 63.3 & 26.7 & 0 \\
\hline Non incidental (12)* & 0 & 16.7 & 41.7 & 33.3 & 8.3 \\
\hline M.G.P. Veloso et al[12] & & & & \multirow{2}{*}{\multicolumn{2}{|c|}{7}} \\
\hline Preoperatively diagnosed(7)* & - & - & - & & \\
\hline No preoperative diagnosis(17)* & - & 5 & - & \multicolumn{2}{|c|}{12} \\
\hline $\begin{array}{l}\text { Waghmare R.S.et al[10] (7)* } \\
\text { (All are unsuspected) }\end{array}$ & 0 & 1 & 6 & 0 & 0 \\
\hline Present study & & & & & \\
\hline Unsuspected (30)* & 20 & 13.3 & 16.7 & 50 & 0 \\
\hline Suspected (24)* & 12.5 & 4.2 & 8.3 & 50 & 25 \\
\hline
\end{tabular}

*Figures in brackets indicate total number of cases in that study.

All the studies in table 5 show that unsuspected or incidental or asymptomatic group show more prevalence of earlier stages than suspected, non incidental or symptomatic cases. However a major difference of our study with all other studies is that only $50 \%$ of the patients in the unsuspected group in our study presented in a stage limited to gallbladder. The corresponding figures for Kimura W et al, L Hu et al and M D' Hondt et al are 70\%, 68.5\% and $73.3 \%$ respectively $[6,11,13]$. This might be due to the influence of genetic and environmental variations between the population of our study and that of other studies.

Another important observation in our study is that well differentiated tumors whether clinically suspected or not shows more tendencies for presentation in earlier stages than moderately and poorly differentiated tumors. Jorge AlboresSaavedra et al[21] also found that 10 of the 13 intramucosal carcinomas in their study were well differentiated.

\section{Conclusion}

A significant portion of gallbladder carcinomas in the present study are found as clinically unsuspected incidental findings on routine gross and microscopic examination. They show relatively less female predominance than suspected cases.

Most of these unsuspected lesions show diffuse thickening of wall as their gross presentation or no grossly identifiable lesion at all. They have a tendency to be better differentiated and in earlier stages than the clinically suspected carcinomas. Well differentiated tumors show more prevalence of earlier stages in the both suspected and unsuspected groups.

Acknowledgement- The authors express their sincere gratitude to Mr Partha Pratim Pathak and Ms Trishna Moni Konwar for their constant support in the technical aspect during conduction of the study. 
Author contribution- PH is involved in study concept, literature search, data acquisition, manuscript preparation, editing and overall supervision. RD has took part in literature search and manuscript preparation. MKS is involved in data acquisition and manuscript preparation. All the three authors have read and approved the final manuscript.

Funding: Nil, Conflict of interest: None initiated, Permission from IRB: Yes

\section{References}

1. Ferlay J, Soerjomataram I, Ervik M, Dikshit R, Eser S, Mathers C, Rebelo M, Parkin D M, Forman D, Bray, F. GLOBOCAN 2012 v1.1, Cancer Incidence and Mortality Worldwide: IARC Cancer Base No.11 [internet]. Lyon, France: International Agency for Research on Cancer; 2014.

2. Randi G, Franceschi S, La Vecchia. Gallbladder cancer worldwide: geographical distribution and risk factors. Int J Cancer 2006. Apr 1; 118(7) : 1591-602.

3. Chapter 2. Leading site of cancer. National cancer Registry Programme. Three-year report of the Population Based Cancer Registries : 2012-2014. Bengaluru, India: Indian council of Medical Research; March, 2016.

4. Ivan Roa, MD, Gilda Ibacache, MT, Sergio Munoz $\mathrm{PhD}$, and Xabier de Aretxabala MD. Gallbladder cancer in Chile. Pathologic Characteristics of Survival and Prognostic Factors : Analysis of 1,366 Cases. Am J Clin Pathol. May 2014; 141(5): 675-682. DOI: 10.1309 /AJCPQT3ELN2BBCKA

5. Poudel R, Singh S K, Basnet S, Dev Kota H, Adhkari S K. Clinicopathological study of gall bladder cancer and its relationship with gall stones. Journal of Society of Surgeons of Nepal. Jul,2016;18(3):46,.Available at: http://www.nepjol.info/index.php/JSSN/article/view/ 15308

6. Kimura W, Nagai H, Kuroda A, Morioka Y. Clinicopathologic study of asymptomatic gallbladder carcinoma found at autopsy. Cancer. 1989 Jul 1;64 (1): 98-103.

7. Juan Jose Barcia MD, Ana Rodriguez MD, Leonerdo Siri MD, Ana Masllorens (Br), Patricia Szwebel(Br), Gisele Acosta MD. Gallbladder carcinoma in the "hospital de clinicas" of Uruguay : 1998-2002. A clinicopathologic study of five cases in 802 cholecystectomies.Annals of Diagnostic Pathology. February 2004; vol.8 (1):1-5.

8. Yujin kwon, Hee Jin Chang. A clinicopathological study of unsuspected carcinomas of gallbladder. Journal of Korean Medical Science. January,1998;12(6):519-22

9. Hamdani N H, Qadri S K, Aggarwalla R, Bhartiya V K, Choudhary S, Debakshi S, Baig S J, Pal N K. Clinicopathological study of gallbladder carcinoma with special reference to gallstones: Our 8-year experience from eastern India. Asian Pac J cancer prev. 2012; 13(11): 5613-7.

10. Waghmare RS, Kamat RN. Incidental Gall Bladder Carcinoma in Patients Undergoing Cholecystectomy: A Report of 7 Cases. J Assoc Physicians India. 2014 Sep; 62 (9):793-6.

11. M. D' Hondt, R. Lapointe, Z Benamira, H Pottel. Carcinoma of gallbladder: pattern of presentation, prognostic factors and survival rate. An 11-year single centre experience. European Journal of surgical oncology (EJSO). June, 2013; vol.39(6): 548-553.

12. VELOSO, Moema Gonçalves Pinheiro and RODRIGUES, Daniel Nava. Gallbladder carcinoma: clinicopathological study of 24 cases. J. Bras. Patol. Med. Lab. [online]. 2011; vol.47, n.4 , pp.439-444.

13. Hu L, Wang B, Liu X, Lv Y. Unsuspected gallbladder cancer: a clinical retrospective study. Arch IranMed.2013Nov;16(11):631-5.doi:0131611/AIM.004.

14. Joon Joon KHOO MBBS, M Path, and Nurul Akmar Misroon MBBS. A clinicopathological study of nine cases of gallbladder carcinoma in 1122 cholecystectomies in Johor, Malayasia. Malayasian J Pathol 2008; 30 (1): 21-26.

15. Manuela Stancu, Irina-Draga Caruntu, Simona Giusca, Gioconda Dobresco. Hyperplasia, metaplasia, dysplasia and neoplasia lesions in chronic cholecystitis -a morphologic study. Romanian Jounal of Morphology and Embryology. 2007; 48(4):335-42.

16. K.S. Lim, C.C. Peters, A Kow and C.H. Tan, "The varying faces of gallbladder carcinoma: pictorial essay" Acta Rediologica. 2012; vol. 53, no. 5, pp494-500. 
17. Goldin RD, Roa JC. Gallbladder cancer: a morphological and molecular update. Histopathology. 2009 Aug;55(2):218-29. doi: 10.1111/j.1365-2559. 2008. 03192.x. Epub 2009 Mar 12.

18. Rosai J. Rosai and Ackerman's Surgical Pathology. 9th edition. Edinburgh: Mosby; 2004.

19. S.E. Mills, D. Carter, J.K. Greenson et al, (Eds.) Sternberg's diagnostic surgical pathology. 5th edition. Lippincott Williams \& Wilkins, Philadelphia; 2010.
20. Mills S E. Histoloy for Pathologist. $3^{\text {rd }}$ ed. Philadelphia PA: Lippincott, Williams and Wilkins; 2007.

21. Jorge Albores-Saavedra, MD, Fredy ChableMontero, MD, David Angels-Albores, Arnold Schwartz, MD, PhD, David S. Klimstra, MD and Donald E Henson, MD. Early Gallbladder Carcinoma. A Clinicopathologic Study of 13 Cases of Intramucosal Carcinoma. Am J. Clin Pathol, 2011; 135 (4): 637- 642 .

\section{How to cite this article?}

Hazarika P, Deka R, Sharma M.K. Pathological differences between clinically suspected and unsuspected gallbladder carcinoma: A 5- year retrospective study.Trop J Path Micro 2017;3(3):235-241.doi: 10.17511/jopm.2017.i3.01. 